\title{
Asset and Operational Energy Performance Rating of a Modern Apartment in Malta
}

\section{Yousif, R. Mucientes Diez \& F. J. Rey Martínez}

Phone: ++ (356) 21650675, Fax: ++ (356) 21652249

E-mail: charles.yousif@um.edu.mt

\section{Website: http://staff.um.edu.mt/cisk1} simulated by DesignBuilder-EnergyPlus software and the EPRDM, which is the official programme for producing energy performance certificates of Maltese residences. In order to use DesignBuilder software, it was necessary to create a weather data file for Malta, known as EPW file. Such a file has not been formally developed before.

\section{The EPW File for Malta}

The construction of the EPW file was made using weather data for the year 2010 provided by the Malta International Airport (MIA) and solar radiation data from the Institute for Sustainable Energy (ISE). A Weather Converter program of EnergyPlus software was run and used to construct the file for Malta and to debug the information.

\section{EPRDM vs. DesignBuilder - EnergyPlus Software}

\section{EPRDM Software}

Monthly average input data the different elements which databases and schedules for form part of the building and the different systems and limitation in the definition of the appliances systems

\section{Single-Zone Buildings}

Unique thermal zone Annual Values \section{DesignBuilder - EnergyPlus} Software

Hourly average input data

\section{Different types of building} Unique/Different thermal zones Annual, monthly, daily, hourly and sub-hourly values Dynamic performance data (EnergyPlus)

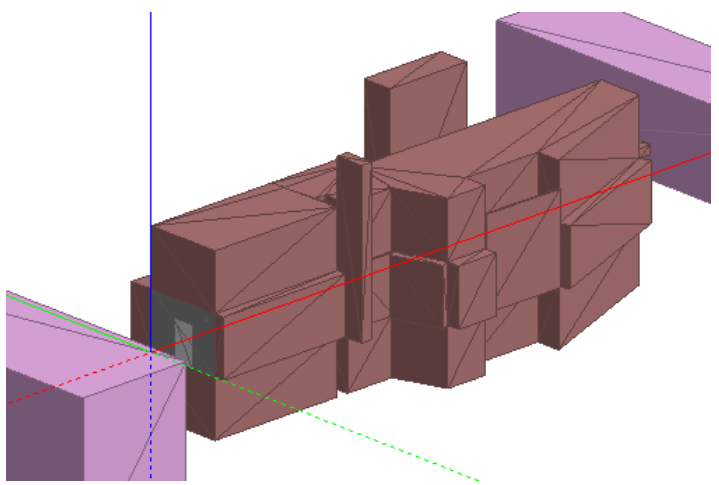

4. Dwelling under Study

The apartment was inhabited in 2010 and it follows a traditional layout with a 5-metre facade and 30-metre depth. The apartment is situated on the first floor and forms part of a block of flats.

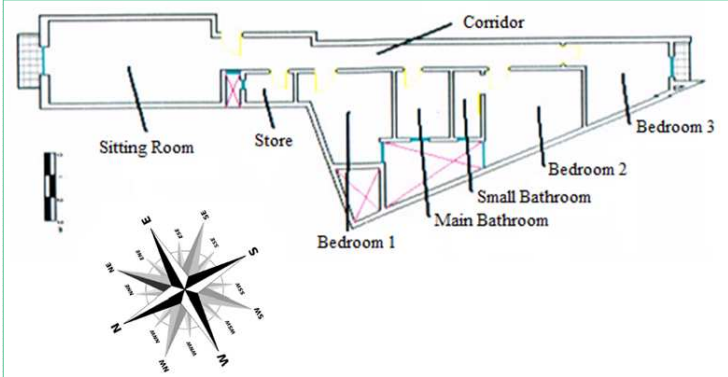

\section{Energy Consumption in the Apartment under Study}

Different data loggers were used to measure the energy consumption in the house. Detailed energy consumption for heating, cooling, water heating, lighting, ventilation and appliances have been collected since March 2011

\section{Results}

A comparison between EPRDM and DesignBuilder - EnergyPlus software was carried out. For this purpose, the option of merged zones was chosen in DesignBuilder in order to simulate a unique thermal zone similar to EPRDM software. Water heating and space heating are the dominant final energy uses in EPRDM (left) and DesignBuilder (Merged Zones, centre) and DesignBuilder (Non-Merged Zones, right). An overestimation of space cooling was observed in DesignBuilder simulations.

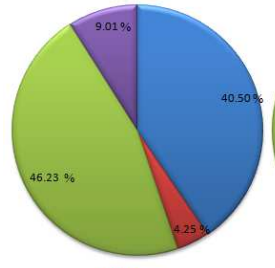

EPRDM

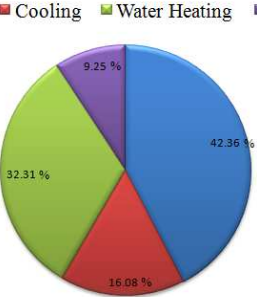

DesignBuilder - EnergyPlus

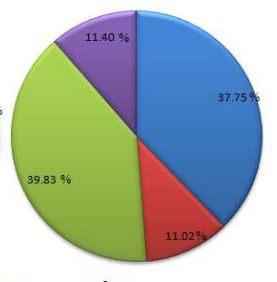

7. External Temperatures in Internal Yards

The difference between the external temperatures on the main street (23N) and in the internal yard $\left(67^{\circ} \mathrm{NW}\right)$ in the warm months indicates that the internal yard works as a heat trap, with high insolation and low wind speeds, thus calling for insulation the single walls overlooking such yards or shaft. In winter, insulation is also recommended as the temperature do cool down to that of the main street.

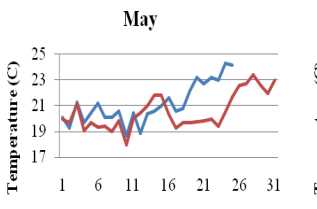

Days

August

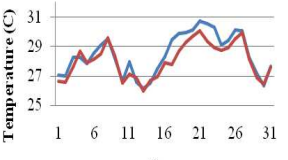

Days

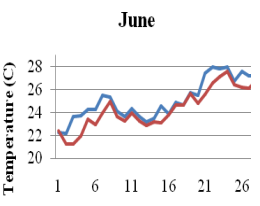

Days

September

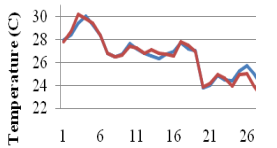

Days

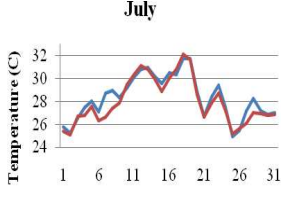

Days

October

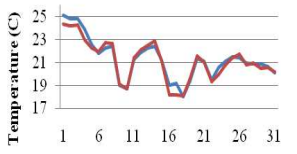

Days

\section{Asset Energy Performance Rating of the Apartment}

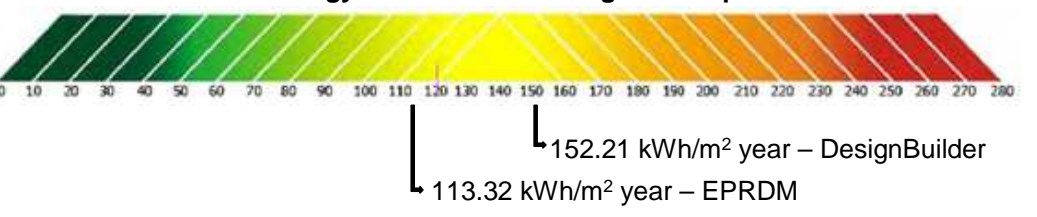

\section{Conclusions}

1. A one-stop guidance manual with a full step-by-step procedure for the creation of any new EPW file has been developed. Such guidance was not found fully explained in any publication.

2. Climate Change could have an effect on typical weather data sets used in EPW files. It is recommended that as much as possible recent data is used.

3. The versatility and flexibility of DesignBuilder - EnergyPlus software could be interesting for the study of non-residential buildings in Malta, since there is no official software for this purpose. Other countries such as Spain have adopted dual software use in their legislation, for the purpose of issuing EPCs.

4. DesignBuilder gave higher Asset Energy Rating values for the dwelling, when compared to actual energy use (Operational Rating). This is better than using a lower Asset Rating of the EPRDM, which could result in an underestimate of the actual performance.

5. Water Heating and energy need for space heating are the highest energy consumers in the dwelling. Insulation of single walls (which form more than $50 \%$ of the total external walls of apartments), as well as the development of a local market for heat pump water heaters should be encouraged and financially supported. 